\title{
Avaliação do extrato hidroalcoólico de Mentha crispa sobre a performance reprodutiva em ratos Wistar
}

\author{
Gustavo Santiago Dimech ${ }^{1}$ Eduardo Silva Gonçalves ${ }^{2}$, Alice Valença de Araújo ${ }^{1}$, Viviane \\ Martins Arruda ${ }^{1}$, Liriane Baratella-Evêncio ${ }^{3}$, Almir Gonçalves Wanderley ${ }^{1 *}$ \\ ${ }^{1}$ Departamento de Fisiologia e Farmacologia, Universidade Federal de Pernambuco, Av. Prof. Moraes Rego, s/n, \\ 50670-901, Recife, PE, Brasil, \\ ${ }^{2}$ Departamento de Ciências Farmacêuticas, Universidade Federal de Pernambuco, Rua Prof. Artur de Sá, s/n, \\ 50740-520, Recife, PE, Brasil, \\ ${ }^{3}$ Departamento de Histologia e Embriologia, Universidade Federal de Pernambuco, Av. Prof. Moraes Rego, s/n, \\ 50670-901, Recife-PE, Brasil
}

\begin{abstract}
RESUMO: A Mentha crispa (Lamiaceae) é conhecida popularmente como hortelã-da-folha-miúda. O extrato hidroalcoólico (EHA) de Mentha crispa, obtido do caule e da folha, possui atividade amebicida (Entamoeba histolytica) e giardicida (Giardia lamblia) e é explorado comercialmente na produção do fitoterápico Giamebil plus ${ }^{\circledR}$. Os efeitos da administração oral subcrônica do EHA de Mentha crispa foram investigados sobre a performance reprodutiva em ratos Wistar adultos. Três grupos de ratos machos ( $\mathrm{n}=6-12 /$ grupo) foram tratados durante 30 dias consecutivos com EHA por via oral nas doses de 0,5 e $1,0 \mathrm{~g} / \mathrm{kg}$ de peso ou água destilada (grupo controle). Em seguida, foram determinados os índices reprodutivos, massa dos órgãos e análise morfológica do testículo, epidídimo e ducto deferente. Os resultados mostram que, durante o período de tratamento, não se observaram sinais de toxicidade ou morte dos animais. Os índices reprodutivos, assim como a massa e as morfologias macro e microscópica dos órgãos não foram modificados pela administração subcrônica do EHA. Dessa forma, conclui-se que a administração subcrônica do extrato hidroalcoólico de Mentha crispa (Giamebil plus ${ }^{\circledR}$ ) não possui atividade contraceptiva sobre o sistema reprodutor de ratos Wistar.
\end{abstract}

Unitermos: Mentha crispa, Lamiaceae, Giamebil plus ${ }^{\circledR}$, performance reprodutiva, toxicologia.

\begin{abstract}
Evaluation of the hydroalcoholic extract of Mentha crispa on the reproductive performance in Wistar rats". Mentha crispa (Lamiaceae) is commonly known as "hortelã-dafolha-miúda". The hydroalcoholic extract (HAE) from the leaves and stem of Mentha crispa possesses amebicidal (Entamoeba histolytica) and giardicidal (Giardia lamblia) activity and it is commercially used in the production of the phytoterapic Giamebil plus ${ }^{\mathbb{Q}}$. The effects of the subchronic administration of the HAE of Mentha crispa were investigated on reproductive performance in adult Wistar rats. Three groups of male rats ( $n=6-12 /$ group) were orally treated daily for 30 consecutive days with the HAE at doses of 0.5 and $1.0 \mathrm{~g} / \mathrm{kg}$ or distilled water (control group). Then, the reproductive indices, the organ weight and the morphologic analysis of testicle, epididymis and vas deferens were determined. There were no signs of toxicity or deaths during the period of treatment. Furthermore, the reproductive indices, the organ weight and the macroscopic and microscopic morphologic analysis of the organs were not altered by subchronic administration of the HAE of Mentha crispa. It shows that the subchronic administration of the HAE of Mentha crispa $\left(\right.$ Giamebil plus ${ }^{\circledR}$ ) did not possess contraceptive activity on the reproductive system of Wistar rats.
\end{abstract}

Keywords: Mentha crispa, Lamiaceae, Giamebil plus ${ }^{\circledR}$, reproductive performance, toxicology.

\section{INTRODUÇÃO}

A Mentha crispa, da família Lamiaceae, é um híbrido originário do cruzamento entre a Mentha spicata L. e a Mentha suaveolens Ehlh (Matos, 1991). Devido à complexidade taxonômica na identificação da espécie, esta também pode ser denominada Mentha $x$ villosa Hudson ou Mentha spicata $\mathrm{L}$. A variação na nomenclatura deve-se a grande facilidade de cruzamento interespecífico no gênero Mentha (Harley, 1973). Essa espécie apresenta-se como uma planta herbácea rasteira, aromática, amplamente distribuída em praticamente todo território nacional, sendo conhecida popularmente como "hortelã-da-folha-miúda", "hortelã-panela" ou "hortelãrasteira" (Braga, 1983; Almeida, 1993).

As folhas e os caules da Mentha crispa são amplamente usados na medicina tradicional por sua propriedade antiparasitária contra Giardia lamblia e Entamoeba histolytica (Mello; Santana; Almeida,1985; Borba et al., 1990; Melo et al., 1992; Santana et al., 1992; Teixeira et al.,1996). Essa atividade culminou no desenvolvimento do fitoterápico Giamebil plus ${ }^{\circledR}$ 
que contém como único princípio ativo o extrato hidroalcoólico (EHA) das partes aéreas.

Algumas espécies de Mentha, em particular a Mentha arvensis, possuem diversos efeitos tóxicos sobre a fertilidade em fêmeas (Kanjanapothi et al., 1981, Mengue; Mentz; Schenkel, 2001) e machos, como alterações da viabilidade dos espermatozóides (Mathur, 1991), ausência de espermatozóide na cauda do epidídimo, redução da prole e da massa dos órgãos reprodutivos em ratos (Sharma; Jacob, 1997, 2001, 2002).

Levando-se em consideração que ambas são do mesmo gênero, pareceu-nos atraente investigar se o EHA de Mentha crispa compartilha dessa atividade contraceptiva sobre o sistema reprodutor de ratos.

\section{METODOLOGIA}

\section{Animais}

Foram utilizados ratos Wistar, Rattus norvegicus, com 2,5-3 meses de idade de ambos os sexos, provenientes do Biotério do Departamento de Fisiologia e Farmacologia da Universidade Federal de Pernambuco. Os animais receberam água e dieta sólida $\left(\right.$ Labina $\left.^{\circledR}\right)$ ad libitum e foram mantidos sob condições controladas de iluminação (ciclo $12 \mathrm{~h}$ claro/escuro) e temperatura ( $24 \pm$ $2{ }^{\circ} \mathrm{C}$ ). Os protocolos experimentais foram aprovados pelo Comitê de Ética em Experimentação Animal (CEEA) da Universidade Federal de Pernambuco (Processo ${ }^{\circ}$ 23076.001798/2003-80).

\section{Material botânico}

As amostras de Mentha crispa foram cultivadas e coletadas pelo Laboratório Hebron S.A. Indústrias Químicas e Farmacêuticas no município de Caruaru, Estado de Pernambuco, Brasil. Uma amostra do material (exsicata de ramos floridos) foi depositada no Herbário do Centro de Ciências Biológicas da Universidade Federal de Pernambuco sob o número 27312. O extrato hidroalcoólico (EHA) foi obtido a partir das partes aéreas da Mentha crispa (100 g), sob agitação freqüente durante $4 \mathrm{~h}$, com álcool a 96\% (100 mL), obtendo-se um rendimento de 20 a $28 \mathrm{mg} / \mathrm{mL}$ de resíduo seco. No extrato padronizado pelo Laboratório Hebron, através de cromatografia em camada gasosa, cromatografia líquida de alta eficiência e cromatografia gasosa com espectrometria de massa, foi identificada a presença de ácidos ursólico, caféico, rosmarínico e luteolina, bem como do glicosídeo sitosterol. Já no óleo essencial, comprovou-se a presença majoritária do composto óxido de piperitenona, além de $\alpha$-pineno, germacreno$\mathrm{D}$, mirceno, 1,8-cineol, limoneno, $\rho$-cimeneno, carvona, cariofileno e humuleno (Pianowski, 2000).

Em nosso laboratório, o EHA fornecido pelo Laboratório Hebron foi concentrado em rota evaporador, liofilizado e armazenado em congelador a $\left(-20^{\circ} \mathrm{C}\right)$ até sua utilização. O liófilo foi ressuspenso em água destilada em concentrações variando de 10 a $20 \%$.

\section{Tratamento dos animais}

Três grupos ( $\mathrm{n}=6-12 /$ grupo) de ratos machos foram tratados durante 30 dias consecutivos, por via oral, com EHA nas doses de 0,5 e 1,0 g/kg (grupos tratados) ou água destilada (grupo controle). Durante o tratamento, a massa corporal dos animais foi registrada semanalmente, e os animais avaliados quanto a sinais clínicos de toxicidade, consumo de água e ração.

Do $25^{\circ}$ ao $30^{\circ}$ dia de administração, os ratos foram transferidos para gaiolas individuais e acasalados com fêmeas não tratadas na proporção (1:1 ou 1:2). A presença de espermatozóides no esfregaço vaginal indicou o sucesso da cópula e foi admitido como $1^{\circ}$ dia de gestação. As ratas foram mantidas em gaiolas individuais e após o nascimento da prole, foram determinadas as variáveis reprodutivas: relação prole/mãe, índice de fertilidade ( ${ }^{\circ}$ de ratas prenhes $/ \mathrm{n}^{\circ}$ de ratas acasaladas), índice de gestação ( $\%$ de fêmeas prenhes com todos os fetos vivos), índice de viabilidade ( $\%$ de sobrevida no $4^{\circ}$ dia de vida), índice de lactação (\% de sobrevida no $21^{\circ}$ $\mathrm{dia} / \mathrm{n}^{\circ}$ de nascimento), massa corporal no $1^{\circ}$ e $21^{\circ}$ dia de vida e observação de aspectos macroscópicos externos e malformação (Elbetieha et al., 1998).

\section{Massa corporal dos órgãos e histologia}

Após o sucesso da cópula, os ratos foram submetidos à eutanásia por inalação excessiva de éter e necropsia para avaliação macroscópica externa dos órgãos reprodutivos. Os testículos, epidídimo e ducto deferente foram cuidadosamente retirados, dissecados, inspecionados macroscopicamente e determinada a massa úmida em balança analítica e expressa em termos de massa relativa g/100g (Vijayalakshmi; Muthulakshmi; Sachdanandam, 2000). Imediatamente após a determinação da massa, os tecidos foram imersos em líquido de Bouin e fixados "in totum" durante 48 horas, à temperatura ambiente. As lâminas histológicas foram preparadas de acordo com Lison (1960) e coradas em hematoxilina/eosina.

\section{Análise estatística}

Os valores foram expressos como média \pm erro padrão da média (epm). As diferenças entre os grupos foram determinadas através da Análise de Variância (ANOVA), seguida, quando detectada diferença, pelo teste de Newman-Keuls. Os índices de fertilidade, gestação, viabilidade e lactação foram analisados através do quiquadrado $\left(\chi^{2}\right)$. O nível de significância para rejeição da hipótese de nulidade foi sempre $\geq$ a $5 \%$. 


\section{RESULTADOS}

Os grupos tratados com extrato de Mentha crispa não apresentaram diferenças significativas na massa corporal em relação ao grupo controle (Figura 1). Durante o período de tratamento não se observou sinais clínicos de toxicidade ou alteração comportamental. Nenhuma morte foi registrada no decurso do tratamento.

Após o período de acasalamento, observou-se que todas as fêmeas levaram a prenhez a termo, sem registro de mortes. Na tabela 1 estão apresentadas as variáveis reprodutivas dos grupos tratados e controle. $\mathrm{O}$ extrato não produziu alteração estatisticamente significativa em nenhuma das variáveis analisadas. $\mathrm{Na}$ prole dos grupos tratados não se constataram alterações macroscópicas externas quando comparada ao grupo controle. O desenvolvimento pós-natal, ganho de massa corporal e atividade geral desses grupos foram similares ao observado com a prole do grupo controle.

As massas da genitália acessória (tabela 2),

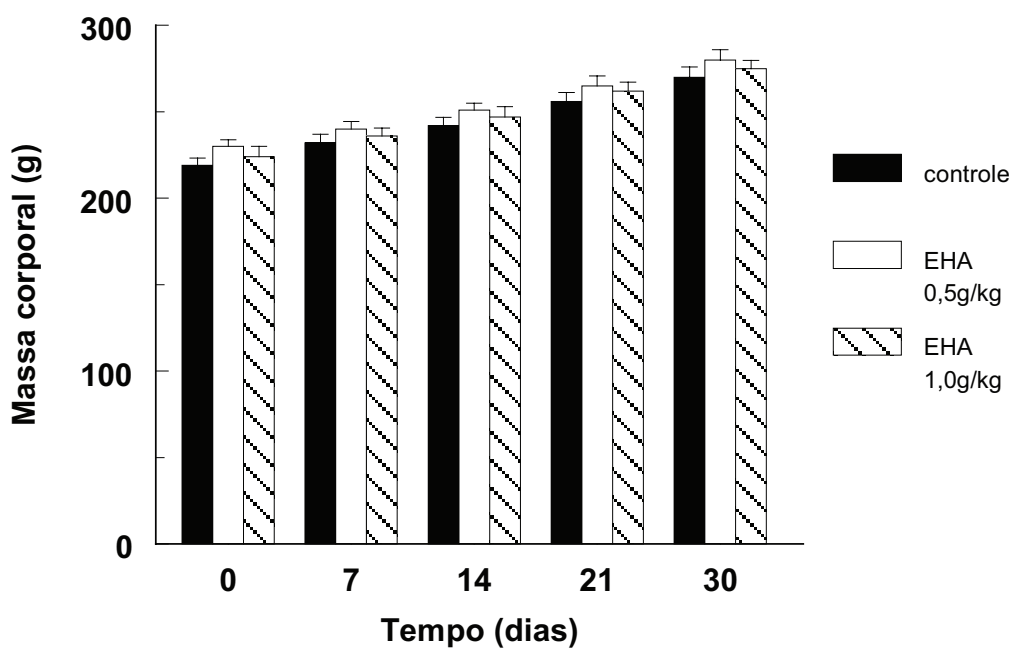

Figura 1. Efeito do extrato hidroalcoólico (EHA) obtido das folhas e caules de Mentha crispa $(0,5$ e $1,0 \mathrm{~g} / \mathrm{kg})$ sobre a massa corporal de ratos Wistar adultos, administrado por via oral durante 30 dias consecutivos. Os valores representam a média \pm epm de respectivamente 12,6 e 10 animais.

assim como as morfologias macroscópicas não foram alteradas pela administração do EHA de Mentha crispa. A análise histológica do testículo não evidenciou nenhuma modificação na estrutura do órgão do grupo tratado com a maior dose em comparação ao grupo controle. Os testículos apresentaram, no espaço intersticial, as células de Leydig de forma arredondada ou poligonal com núcleo central e citoplasma acidófilo, além do tecido conjuntivo com sua diversidade característica. As células germinativas e espermatozóides nos túbulos seminíferos apresentaram morfologia normal e em diferentes estágios de desenvolvimento. As células de Sertoli mostraram-se claras, com o núcleo triangular e citoplasma característico (Figura 2). O epidídimo mostrou-se com morfologia normal e, na luz deste órgão, evidenciam-se os espermatozóides (Figura 3). Assim, não foram observadas alterações histológicas nos órgãos reprodutivos do grupo tratado.

\section{DISCUSSÃO}

Os animais tratados com extrato de Mentha crispa não apresentaram alterações no ganho de massa corporal em relação ao grupo controle, mesmo quando foram usadas, respectivamente, doses 116 e 232 vezes maiores do que aquela recomendada pelo Laboratório. Estes dados indicam que, considerando o período de tratamento, o extrato não apresenta efeitos tóxicos gerais. Além disso, dados do nosso laboratório mostraram que a $\mathrm{DL}_{50}$ obtida do extrato por via oral está acima de $4,0 \mathrm{~g} / \mathrm{kg}$.

Estudos de fertilidade avaliam o resultado do acasalamento após o período de pré-tratamento em pelo menos um dos sexos. A avaliação da fertilidade e da conseqüente prenhez fornece importantes informações das conseqüências funcionais do agente químico sobre o sistema reprodutor (US EPA, 1996). Os resultados demonstram que o tratamento no período préacasalamento com EHA de Mentha crispa não alterou a fertilidade dos ratos, uma vez que todos os valores das variáveis reprodutivas analisadas foram similares ao obtido no grupo controle.

Sharma e Jacob (1996 e 2001) mostraram que o extrato aquoso de $M$. arvensis suprime a fertilidade de camundongos machos após a administração por

Rev. Bras. Farmacogn. Braz J. Pharmacogn. 16(2):abr/jun. 2006 
Tabela 1. Variáveis de reprodução obtidas através do acasalamento entre ratos Wistar do grupo controle e dos grupos tratados (machos tratados x fêmeas não tratadas) por via oral durante 30 dias com EHA das partes aéreas de Mentha crispa $(0,5$ e 1,0 $\mathrm{g} / \mathrm{kg})$.

\begin{tabular}{|c|c|c|c|}
\hline Variáveis Reprodutivas & Controle & EHA $0,5 \mathrm{~g} / \mathrm{kg}$ & EHA $1,0 \mathrm{~g} / \mathrm{kg}$ \\
\hline Machos acasalados & 12 & 06 & 10 \\
\hline Fêmeas acasaladas & 23 & 06 & 17 \\
\hline Fêmeas prenhas & 21 & 06 & 16 \\
\hline Duração da gestação (dias) ${ }^{1}$ & $21,0 \pm 0,7$ & $20,8 \pm 0,5$ & $21,0 \pm 0,8$ \\
\hline Relação prole/mãe & $9,5 \pm 0,3$ & $9,3 \pm 0,9$ & $8,4 \pm 0,9$ \\
\hline Índice de fertilidade (\%) & $91,3 \%$ & $100 \%$ & $94,1 \%$ \\
\hline $\begin{array}{l}\left(\mathrm{n}^{\circ} \text { de ratas prenhes } / \mathrm{n}^{\circ} \text { de ratas acasaladas) }\right. \\
\text { Indice de gestação }(\%) \\
(\% \text { de fêmeas prenhes com todos os fetos } \\
\text { vivos) }\end{array}$ & $100 \%$ & $100 \%$ & $100 \%$ \\
\hline $\begin{array}{l}\text { Índice de viabilidade }(\%) \\
\left(\% \text { de sobrevida no } 4^{\circ} \text { dia de vida) }\right.\end{array}$ & $96,9 \%$ & $100 \%$ & $100 \%$ \\
\hline $\begin{array}{l}\text { Índice de lactação }(\%) \\
\left(\% \text { de sobrevida no } 21^{\circ} \text { dia } / n^{\circ} \text { de }\right. \\
\text { nascimento) }\end{array}$ & $100 \%$ & $98,2 \%$ & $100 \%$ \\
\hline Massa corporal $1^{\circ}$ dia $(g)^{1}$ & $5,6 \pm 0,4$ & $5,9 \pm 0,6$ & $5,7 \pm 0,2$ \\
\hline Massa corporal $21^{\circ}$ dia $(\mathrm{g})^{1}$ & $47,5 \pm 1,7$ & $44,7 \pm 0,8$ & $41,4 \pm 1,4$ \\
\hline
\end{tabular}

${ }^{1}$ Os valores representam a média \pm epm.

Tabela 2. Efeito da administração oral do extrato hidroalcoólico (EHA) das partes aéreas de Mentha crispa (0,5 e 1,0 g/kg) sobre a massa $(\mathrm{g} / 100 \mathrm{~g})$ dos órgãos genitais acessórios de ratos Wistar adultos.

\begin{tabular}{lccc}
\hline Genitais Acessórios & Controle & EHA 0,5 g/kg & EHA 1,0 g/kg \\
\hline Testículo & $0,54 \pm 0,02$ & $0,58 \pm 0,03$ & $0,55 \pm 0,01$ \\
Epidídimo & $0,21 \pm 0,01$ & $0,20 \pm 0,01$ & $0,18 \pm 0,01$ \\
Ducto deferente & $0,022 \pm 0,001$ & $0,022 \pm 0,002$ & $0,023 \pm 0,002$ \\
\hline
\end{tabular}

Os valores representam a média \pm epm de respectivamente 12,6 e 10 animais.

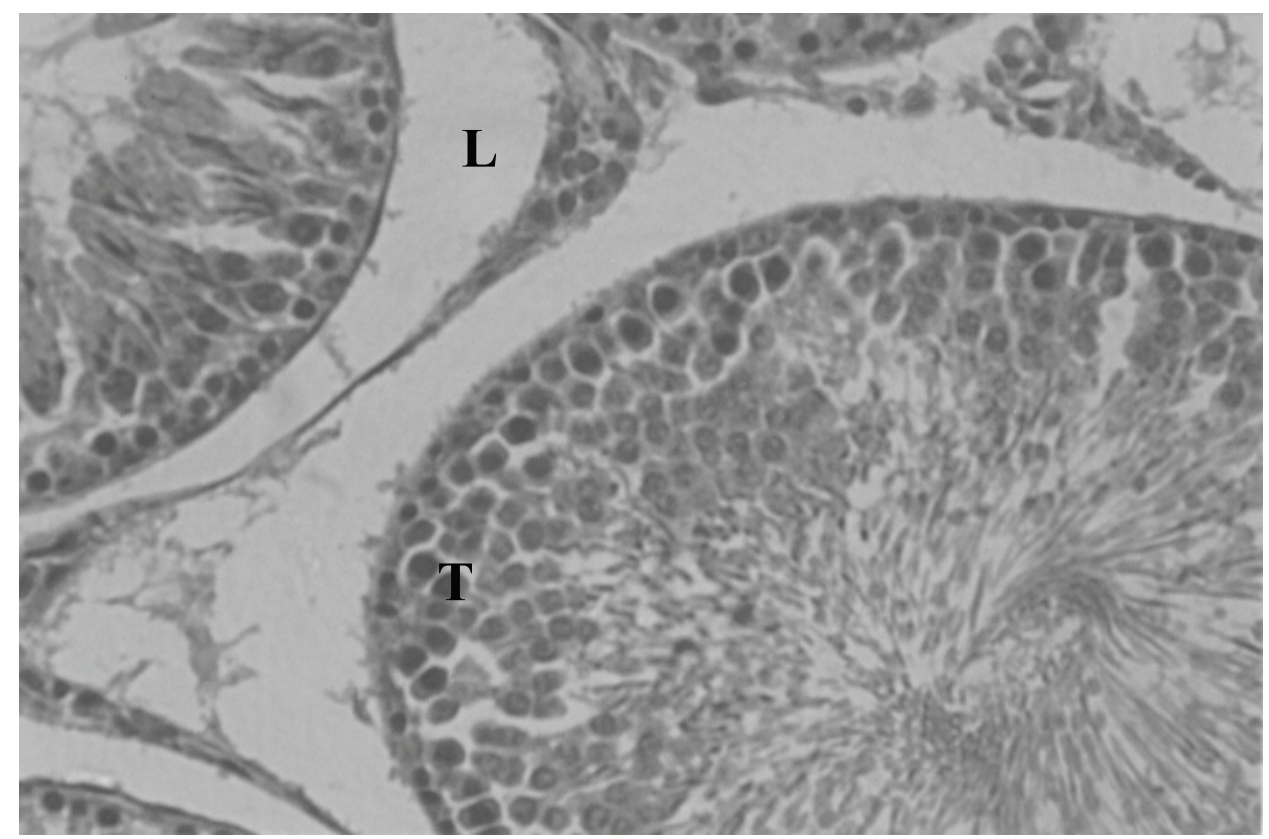

Figura 2. Fotomicrografia do testículo de rato submetido ao tratamento durante 30 dias consecutivos por via oral com EHA das partes aéreas de Mentha crispa $(1,0 \mathrm{~g} / \mathrm{kg})$. L: células de Leydig; T: túbulos seminíferos (obj 40x). 


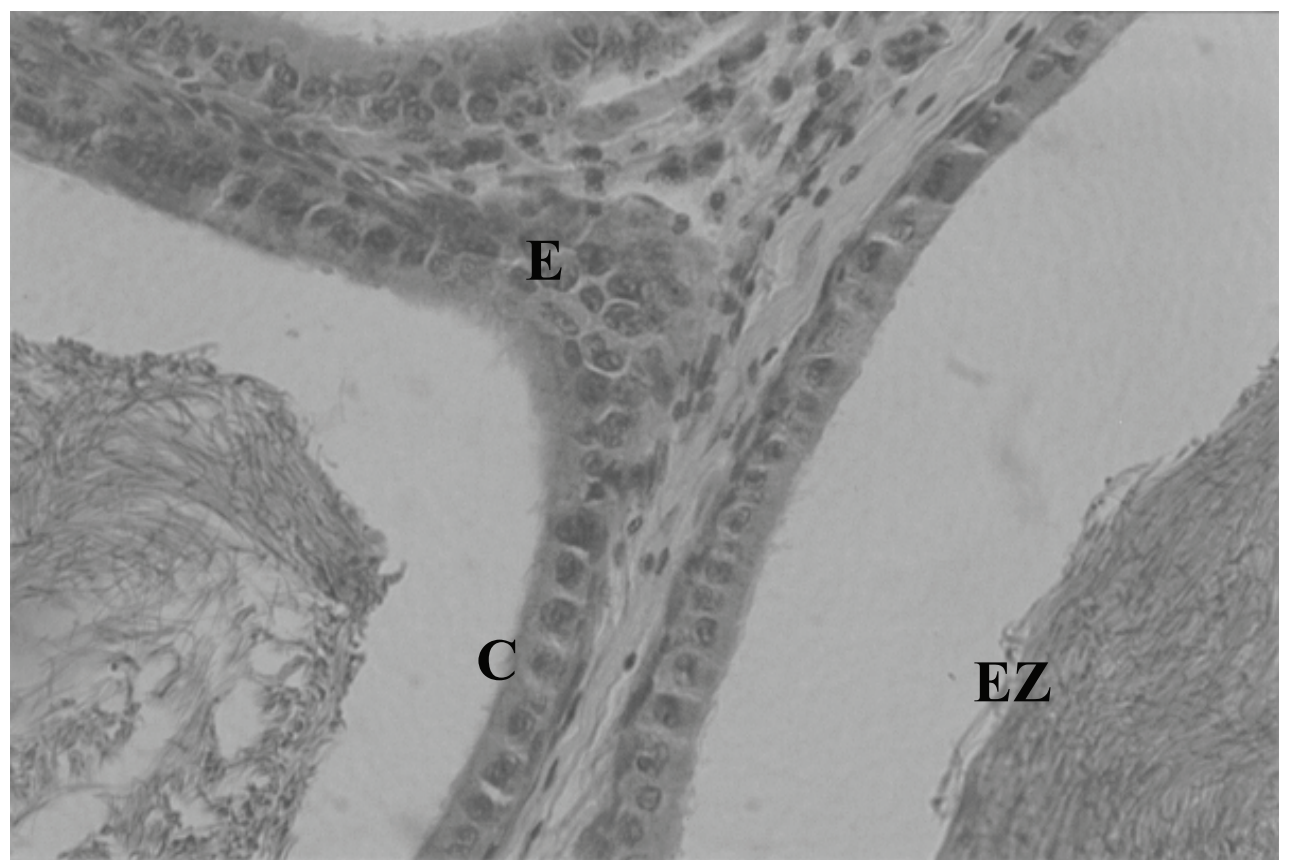

Figura 3. Fotomicrografia do epidídimo de rato submetido ao tratamento durante 30 dias consecutivos por via oral com EHA das partes aéreas de Mentha crispa $(1,0 \mathrm{~g} / \mathrm{kg})$. E - epitélio; EZ - espermatozóide; C - cápsula (Obj. 40x).

20 dias, além de reduzir o número e motilidade dos espermatozóides e a massa dos testículos e epidídimo.

As ausências de alteração sobre a massa e morfologia dos órgãos reprodutivos reforçam a idéia de que o EHA de $M$. crispa não possui ação contraceptiva em ratos, uma vez que, nessa espécie, reduções das massas do testículo e do epidídimo são indicadores que revelam redução da fertilidade ou atividade contraceptiva (Quian, 1984, Jahn; Günzel, 1997, Gupta et al., 2001). Juntos, esses tecidos são responsáveis pela formação e maturação dos espermatozóides, além da produção de hormônios (Moundipa et al., 1999).

Em conclusão, as evidências apontam para uma ausência de efeitos contraceptivos por via oral do extrato hidroalcoólico de Mentha crispa.

\section{AGRADECIMENTOS}

Ao Laboratório Hebron, pelo fornecimento do EHA de Mentha crispa e à Rejane de Souza Silva, pelo apoio técnico.

\section{REFERÊNCIAS}

Almeida ER 1993. Plantas medicinais brasileiras conhecimento popular e científico. São Paulo: Henus editora ltda.

Borba MOP, Silva JF, Montenegro L, Jugmann P, Cavalcanti MM, Alburquerque PMS 1990. Frações ativas da Mentha crispa sobre camundongos albinos swiss infectados com Schistosoma mansoni cepa são lourenço da mata (slm) parte I. in: XI Simpósio de Plantas Medicinais do Brasil. João Pessoa, Brasil.

Braga R 1983. Plantas do Nordeste - Especialmente do Ceará. $4^{\mathrm{a}}$ ed. Natal: Editora Universitária da Universidade Federal do Rio Grande do Norte.

Elbetieha A, Al-Hamood MH, Alkofahi A, Bataineh H 1998. Reproductive toxicology potentials of salvia fruticosa (Labiatae) in rats. J Ethnopharmacol 61: 67-74.

Gupta RS, Yadav VP, Dixit VP, Dobhal MP 2001. Antifertility studies of Colebrookia oppositifolia leaf extract in male rats with special reference to testicular cell population dynamics. Fitoterapia 72: 236-245.

Harley RM 1973. Mints. In: Plants wild and cultives (Green PS ed.) Kew, Royal Botanic Gardens.

Jahn AI, Gunzel PKH 1997. The value of spermatology in male reproductive toxicology: do spermatologic examinations in fertility studies provide new and additional information relevant for safety assessment. Reprod Toxicol 11: 171-178.

Kanjanapothi D, Smitasiri Y, Panthong A, Taesotikul T, Rathnapanone V 1981. Postcoital antifertility effect of Mentha arvensis. Contraception 24: 559-567.

Lison L 1960. Histochimie et cytochimie animales. Paris, gauthiers - villars.

Mathur R 1991. Fructolysis effect of 50\% ethanolic extract of Mentha arvensis linn. (leaves) in seminal vesicles of rat. Acta European Fertility 22: 219-20.

Matos FJA 1991. Farmácias vivas. Fortaleza, ed. Universidade Federal do Ceará.

Melo AM, Pinho S, Santana CF, Santos ER, Souza IA 1992. Primeiras observações sobre o uso da Mentha crispa em tricomoníase urogenital. XII Simpósio de Plantas Medicinais do Brasil. Curitiba, Brasil.

Mello AC, Santana CF, Almeida ER 1985. Primeiras observações sobre o uso da Mentha crispa e outros vegetais no tratamento das parasitoses intestinais. Encontro Anual do Centro de Ciências Biológicas da Universidade Federal de Pernambuco. Recife, Brasil. 
Mengue SS, Mentz LA, Schenkel EP 2001. Uso de plantas medicinais na gravidez. Rev Bras Farmacogn 11: 2135.

Moundipa FP, Kamtchouing P, Koueta N, Tantchou J, Foyang NPR, Mbiapo FT 1999. Effects of aqueous extracts of Hibiscus macranthus and Basella alba in mature rat testis function. J Ethnopharmacol 65: 133-139.

Pianowski LF 2000. Desenvolvimento farmacêutico de um produto fitoterápico. Porto, $82 \mathrm{p}$. Tese de Doutorado - Universidade do Porto.

Quian SZ 1984. Gossypol - a potential antifertility agent for males. Annu Rev Pharmacol Toxicol 24: 329-360.

Santana CF, Almeida ER, Santos ER, Souza IA 1992. Action of Mentha crispa hidroethanolic extract in patients bearing intestinal protozoan. Fitoterapia 63: 409410.

Sharma N, Jacob D 1996. Fertility supression of male mouse after administration of mint leaf extract. Phytother Res 10: $175-177$

Sharma N, Jacob D 1997. Antispermatogenic effect of cromatographic fractions isolated from petroleum ether extract of Mentha arvensis leaf in the albino mouse. Phytother Res 11: 386-388.

Sharma N, Jacob D 2001. Antifertility investigation and toxicological screening of the petroleum ether extract of leaves of Mentha arvensis in male albino mice. $J$ Ethnopharmacol 75: 5-12.

Sharma N, Jacob D 2002. Assessment of reversible contraceptive efficacy of methanol extract of Mentha arvensis leaves in male albino mice. J Ethnopharmacol 80: 9-13.

U.S. Environmental Protection Agency (US EPA), 1996. Guidelines for reproductive risk assessment [EPA/630/ R-96/009].

Teixeira MJ, Holanda Filha JG, Santos FA, Fonseca SGC, Rao VS, Silveira ER, Matos FJA, Pompeu MML 1996. Avaliação do efeito leishmanicida, in vitro, de óleos essenciais e princípios ativos de plantas medicinais brasileiras. $X V$ Simpósio de Plantas Medicinais do Brasil, Águas de Lindóia, Brasil.

Vijayalakshmi T, Muthulakshmi V, Sachdanandam P 2000. Toxic studies on biochemical parameters carried out in rats with serankottai nei, a siddha drug-milk extract of Semecarpus anacardium nut. $J$ Ethnopharmacol 69: 9-15. 